\title{
Angiotensin II Stimulates Early Proximal Bicarbonate Absorption in the Rat by Decreasing Cyclic Adenosine Monophosphate
}

\author{
Fu-Ying Liu and Martin G. Cogan \\ Department of Medicine and Cardiovascular Research Institute, University of California \\ and Veterans Administration Medical Center, San Francisco, California 94121
}

\begin{abstract}
These studies explored the hypothesis that angiotensin II increases bicarbonate absorption in the proximal convoluted tubule (PCT) by decreasing intracellular CAMP. In vivo microperfusion was performed in rat PCT with measurements of bicarbonate absorption and of tubular fluid cAMP delivery, as a reflection of intracellular cAMP. Intravenous angiotensin II potently increased $S_{1}$ PCT bicarbonate absorption (348 \pm 11 to $588 \pm 8 \mathrm{peq} / \mathrm{mm} \cdot \mathrm{min}, P<0.001)$ and decreased tubular fluid cAMP (18 \pm 2 to $12 \pm 2 \mathrm{fmol} / \mathrm{mm} \cdot \mathrm{min}, P<0.05)$. Parathyroid hormone had the expected opposite effects, which were additive to those of angiotensin II. Over a wide range of hormonal activities, there was an excellent inverse relationship between hormonally modulated bicarbonate absorption and CAMP delivery. Pertussis toxin pretreatment significantly attenuated (by 35-45\%) the angiotensin-induced increase in bicarbonate absorption and decrease in cAMP delivery, indicating $G_{i}$-protein intermediation. Luminal dibutyryl cAMP abolished the transport response to angiotensin II. In conclusion, these in vivo results suggest angiotensin II stimulates bicarbonate $\mathbf{a b}$ sorption in the $S_{1}$ PCT by a $G_{i}$-mediated depression in intracellular cAMP.
\end{abstract}

\section{Introduction}

The early, $S_{1}$ proximal convoluted tubule $(\mathrm{PCT})^{1}$ is the site for reabsorption of $50 \%$ of the normal filtered load of bicarbonate (1). Recently, we found that $S_{1}$ PCT cells had angiotensin II receptors in high density and angiotensin II was a potent regulator of bicarbonate reabsorption in this nephron segment $(2,3)$.

The cellular second messenger system responsible for transducing angiotensin II's powerful control of $S_{1}$ PCT epithelial cell transport has not been explained. A well-described signaling system used by angiotensin II in vascular smooth muscle cells to induce contraction and to activate the $\mathrm{Na}^{+} / \mathrm{H}^{+}$ antiporter is phosphatidylinositol breakdown, with subsequent rise in intracellular calcium and activation of protein kinase $C$

Address reprint requests to Dr. Martin G. Cogan, Nephrology Section, Medical Services $111 \mathrm{~J}$, Veterans Administration Medical Center, 4150 Clement St., San Francisco, CA 94121.

Received for publication 10 October 1988 and in revised form 1 February 1989.

1. Abbreviations used in this paper: $\mathrm{G}_{\mathrm{i}}$, inhibitory $\mathrm{G}$ protein; $\mathrm{G}_{\mathrm{s}}$, stimulatory G protein; PCT, proximal convoluted tubule; PT, pertussis toxin; PTX, parathyroidectomy.

The Journal of Clinical Investigation, Inc.

Volume 84, July 1989, 83-91
$(4,5)$. In PCT epithelial cells, angiotensin II can increase phosphatidylinositol turnover (6) and, in relatively high concentrations $\left(10^{-8}-10^{-5} \mathrm{M}\right)$, can increase intracellular calcium $(7,8)$, but there has been no correlation of these responses with transport. If angiotensin II caused activation of protein kinase C in PCT cells, stimulation of the $\mathrm{Na}^{+} / \mathrm{H}^{+}$antiporter might be expected (9). However, when phorbol ester was perfused in the in vitro rabbit $P C T$ to activate protein kinase $C$, bicarbonate transport was actually inhibited (10).

Another signaling system used by angiotensin II in many cells (11-24) including those of the PCT (25) involves reduction of adenylate cyclase activity to lower intracellular cAMP concentration. No correlation with renal epithelial cell ion transport has been yet made with this angiotensin II signaling mode. If angiotensin II reduced intracellular cAMP in $S_{1}$ PCT cells, a stimulation of bicarbonate transport might be expected, mirroring the effects of PTH. PTH raises intracellular cAMP and inhibits $\mathrm{Na}^{+} / \mathrm{H}^{+}$activity and PCT bicarbonate absorption $(26,27)$.

The purpose of these studies was to provide combined physiologic-biochemical evidence in vivo that reduction in intracellular cAMP is the signal transduction system by which angiotensin II augments PCT bicarbonate absorption. We capitalized on the fact that CAMP is transported with first-order kinetics out of all metazoan cells (28), including cells derived from the PCT (29). Extracellular cAMP egression is therefore an excellent reflection of mean intracellular cAMP concentration. Using in vivo microperfusion in the rat $S_{1} P C T$, we found an excellent inverse correlation of bicarbonate absorption with extracellular cAMP appearance in response to variations in angiotensin II and/or PTH activities.

\section{Methods}

In vivo microperfusion. Preparation of the Munich-Wistar rat and PCT microperfusion techniques have been previously reported from this laboratory $(2,3,30)$. Microperfusion was performed in both the early and late portions of a single PCT for each rat. The entire PCT was initially mapped by injecting a small oil droplet into Bowman's space. First studied was the late portion of the PCT, the $S_{2}$ subsegment, defined as the PCT $2.5-5 \mathrm{~mm}$ from the glomerulus (31). After venting the tubule proximally for escape of endogenous ultrafiltrate, an oil block was inserted and a thermally insulated microperfusion pump (Wolfgang Hampel, Berlin, FRG) was used for orthograde perfusion at $30 \mathrm{nl} / \mathrm{min}$. After inserting another oil block to prevent retrograde contamination, timed collections of 3-8 min were made with a second pipette. The same procedures for perfusion and collection were then performed in the early portion of the same PCT, the $S_{1}$ subsegment, defined as the initial $\mathrm{mm}$ of PCT from the glomerulus (31).

The perfusion solution was the standard glomerular ultrafiltratelike solution (in millimolar): $\mathrm{NaCl}, 120 ; \mathrm{NaHCO}_{3}, 25 ; \mathrm{KCl}, 5 ; \mathrm{MgSO}_{4}$, $1 ; \mathrm{CaCl}_{2}, 1.8 ; \mathrm{Na}_{2} \mathrm{PO}_{4}, 1$; glucose, 5 ; alanine, 5 ; and urea, $5(2,3,30)$. The solution was gassed with $93 \% \mathrm{O}_{2} / 7 \% \mathrm{CO}_{2}$ and contained $0.1 \%$ fast 
green dye and exhaustively dialyzed $\left[\right.$ methoxy- $\left.{ }^{3} \mathrm{H}\right]$ inulin for measurement of water absorption. In indicated protocols below, $10^{-5} \mathrm{M}$ dibutyryl-cAMP or -cGMP or $10^{-12} \mathrm{M}$ angiotensin II was also added to the perfusate.

There were two paired sets of $S_{1}$ and $S_{2}$ PCT collections in each experiment. After the first set of microperfusion collections, a drug or hormone infusion was usually begun and, after a 45-60-min equilibration period, the second set of $S_{1}$ and $S_{2} P C T$ microperfusion collections was obtained.

After completing all collections, the entire tubule was injected with liquid microfil, the kidney was dissolved in acid, and the microfil casts were dissected and photographed for measurement of perfused length. The volume of collected sample was measured and aliquots were removed for determination of total $\mathrm{CO}_{2}$ and cAMP concentrations and of radioactivity.

Protocols. There were 11 two-period protocols, each with five animals (except No. 4, which had a total of six animals): (1) In control/ control experiments, measurements were made during two time-control periods without hormone infusion. (2) In control/angiotensin II, the first measurements were made in a control period and the second after an intravenous infusion of angiotensin II (Asn', $\mathrm{Val}^{5} \mathrm{AII}$, Sigma Chemical Co.) at $20 \mathrm{ng} / \mathrm{kg} \cdot \mathrm{min}$, a subpressor dose that does not significantly alter systemic or glomerular hemodynamics $(2,3)$. (3) In control/PTH, the first measurements were made in a control period and the second after an intravenous infusion of PTH (1-34 bovine PTH, Sigma Chemical Co.) at $0.5 \mu \mathrm{g} / \mathrm{kg} \cdot \mathrm{min}$, an infusion rate that achieves a pharmacologic systemic concentration. (4A) Angiotensin II/angiotensin II + PTH. The first measurements were made after intravenous angiotensin II administration $(20 \mathrm{ng} / \mathrm{kg} \cdot \mathrm{min})$ and the second after continued angiotensin II plus intravenous PTH administration $(0.5 \mu \mathrm{g} / \mathrm{kg} \cdot \mathrm{min})$. (4B) PTH/PTH + angiotensin II. The first measurements were made after intravenous PTH $(0.5 \mu \mathrm{g} / \mathrm{kg} \cdot \mathrm{min})$ and the second after continued PTH plus intravenous angiotensin II ( $20 \mathrm{ng} / \mathrm{kg} \cdot \mathrm{min})$. (5) Saralasin/saralasin + PTH. The first measurements were made after intravenous saralasin $(1 \mu \mathrm{g} / \mathrm{kg} \cdot \mathrm{min}$, Sigma Chemical Co.), as previously described (2), and the second after continued saralasin plus intravenous PTH $(0.5 \mu \mathrm{g} / \mathrm{kg} \cdot \mathrm{min})$. (6) Parathyroidectomy (PTX)/PTX + angiotensin II. The first period was performed $3 \mathrm{~h}$ after acute surgical parathyroidectomy and the second after addition of intravenous angiotensin II $(20 \mathrm{ng} / \mathrm{kg} \cdot \mathrm{min})$. (7) Pertussis Toxin (PT)/PT + angiotensin II. The animals were prepared 3-5 d before study by the intravenous infusion of pertussis toxin $(20 \mu \mathrm{g} / \mathrm{kg}$ i.v., Sigma Chemical Co.), according to published protocols $(24,32)$. The first period of measurements were made in these PT-pretreated animals during control conditions and the second after intravenous angiotensin II administration (20 ng/kg • min). (8) Luminal dibutyryl cAMP/luminal dibutyryl cAMP plus angiotensin II. The first period was performed with dibutyryl cAMP $\left(10^{-5} \mathrm{M}\right.$, Sigma Chemical Co.) added to the luminal perfusate and the second with continued luminal dibutyryl AMP administration plus infusion of intravenous angiotensin II $(20 \mathrm{ng} / \mathrm{kg} \cdot \mathrm{min})$. The dose of dibutyryl cAMP was chosen on the basis of preliminary experiments that showed that it gave a maximal physiologic response. (9) Luminal dibutyryl cGMP/luminal dibutyryl cGMP plus angiotensin II. The first period was performed with dibutyryl cGMP $\left(10^{-5} \mathrm{M}\right.$, Sigma Chemical Co.) added to the luminal perfusate and the second with continued luminal dibutyryl cGMP administration plus infusion of intravenous angiotensin II ( $20 \mathrm{ng} / \mathrm{kg} \cdot \mathrm{min})$. (10) Control $(30 \mathrm{nl} / \mathrm{min}) / \mathrm{con}$ trol (45 $\mathrm{nl} / \mathrm{min})$. The first period was performed in a control period with the usual luminal perfusion rate of $30 \mathrm{nl} / \mathrm{min}$, and the second after increase in luminal perfusion rate to $45 \mathrm{nl} / \mathrm{min}$ to increase bicarbonate absorption, as previously described (30). (11) Control/luminal angiotensin II. The first period was performed in a control period and the second following angiotensin II $\left(10^{-12} \mathrm{M}\right)$ added to the luminal perfusate, as previously described (3).

Tubular fluid cAMP. The appearance of cAMP in PCT tubular fluid was used as an index of the time-integrated intracellular cAMP concentration $(28,29)$. We first demonstrated that the amount of cAMP appearing in tubular fluid in vivo could be measured using the standard RIA (New England Nuclear, Boston, MA). 50\% displacement of the tracer CAMP in the acetylated protocol of this assay was $\sim 100$ fmol/tube. The normal cAMP flux into the microperfused $S_{1} P C T$ was $\sim 12-16 \mathrm{fmol} / \mathrm{min}$ or $\sim 60-80 \mathrm{fmol} / 5-\mathrm{min}$ collection, and thus easily detected.

cAMP collected in the tubular fluid is an accurate reflection of cAMP egression from PCT cells assuming cAMP is neither reabsorbed by the cells nor secreted from the peritubular blood. Although existing evidence supports the lack of reabsorption and transepithelial secretion of cAMP in various species (33-35), further studies were performed to document this specifically in the $S_{1}$ and $S_{2} P C T$ of the rat. The possible reabsorption of cAMP in the PCT was first evaluated using $\left[{ }^{3} \mathrm{H}\right]$ cAMP (ICM Biomedicals, Irvine, CA) in the perfusate $(677 \mathrm{cpm} / \mathrm{min})$. The collected-to-perfused ratio of $\left[{ }^{3} \mathrm{H}\right] \mathrm{cAMP}$ was $1.005 \pm 0.006$ in the $S_{1}$ PCT $(n=3)$ and $1.002 \pm 0.002$ in the $\mathrm{S}_{2} \mathrm{PCT}(n=3)$. These ratios were indistinguishable from unity, indicating lack of cAMP reabsorption.

The possibility of unidirectional blood-to-lumen cAMP movement was next evaluated by infusing ${ }^{3} \mathrm{H}$-cAMP intravenously $(0.6 \mu \mathrm{Ci} / \mathrm{min})$ while performing microperfusion in the $S_{1}$ and $S_{2}$ PCT $(n=3)$. Collected $\left[{ }^{3} \mathrm{H}\right]$ cAMP counts per minute in each segment was $0.2-0.5 \%$ of that simultanously measured in blood. The apparent flux coefficient was 2.1 and $1.3 \times 10^{-7} \mathrm{~cm}^{2} / \mathrm{s}$ in the $S_{1}$ and $S_{2} P C T$, respectively. Because the measured plasma concentration of cAMP was $15 \mathrm{nM}$, this cAMP transepithelial flux could account for 0.01-0.02 fmol/ $\mathrm{mm} \cdot \mathrm{min}$, or $<1 \%$ of the actual cAMP appearance during microperfusion in the $S_{1}$ and $S_{2}$ PCT segments. Thus, most collected tubular fluid cAMP in the microperfused rat PCT derived from cellular egression, not from the blood.

Other analyses. Total $\mathrm{CO}_{2}$ was measured by microcalorimetry as previously described $(2,3,30)$ and $\left[\right.$ methoxy- $\left.{ }^{3} \mathrm{H}\right]$ inulin was measured by scintillation counting.

Calculations and statistics. Total $\mathrm{CO}_{2}$ was assumed to principally represent bicarbonate. Bicarbonate absorption, $J_{\mathrm{HCO}_{3}}$, was the difference in the absolute amounts of bicarbonate perfused and collected (2, 3,30 ). Tubular fluid cAMP delivery, $T F_{\text {cAMP }} V$, was the product of the collected cAMP concentration and flow rate. Data are presented as mean \pm SEM. Significance was assessed using the paired $t$ test for results obtained in the same tubule segment.

\section{Results}

In the following studies, bicarbonate absorption $\left(J_{\mathrm{HCO}_{3}}\right)$ was correlated with tubular fluid cAMP delivery $\left(T F_{\text {cAMP }} V\right)$ in microperfused $S_{1}$ and $S_{2}$ PCT during various hormonal manipulations. The tubular fluid cAMP was used as an index of mean intracellular cAMP concentration $(28,29)$.

As shown in Table I and Fig. 1, time controls showed no change in $S_{1}$ PCT bicarbonate absorption or cAMP delivery. Intravenous angiotensin II markedly increased $S_{1}$ PCT bicarbonate absorption $(348 \pm 11$ to $588 \pm 8 \mathrm{peq} / \mathrm{mm} \cdot \mathrm{min}, P$ $<0.001$ ) with a significant decrease in cAMP delivery $(17.9 \pm 2.0$ to $11.7 \pm 1.5 \mathrm{fmol} / \mathrm{mm} \cdot \min , P<0.05)$. PTH administered intravenously had the expected opposite effects ( $351 \pm 5$ to $194 \pm 12 \mathrm{peq} / \mathrm{mm} \cdot \min , P<0.001$, and $18.1 \pm 0.5$ to $23.5 \pm 0.9 \mathrm{fmol} / \mathrm{mm} \cdot \mathrm{min}, P<0.001$, respectively).

Further studies explored the additivity, interaction, and range of the hormonally induced changes in bicarbonate absorption and cAMP egression. As shown in Table 1 and Fig. 2, after infusion of either angiotensin II and PTH separately, coadministration of both hormones tended to cancel each other's actions (with a slight favoring toward angiotensin II), returning both bicarbonate absorption and cAMP delivery to values close to control $(422 \pm 14 \mathrm{peq} / \mathrm{mm} \cdot \mathrm{min}$ and $15.8 \pm 0.7$ $\mathrm{fmol} / \mathrm{mm} \cdot \mathrm{min}$, respectively). Inhibition of endogenous angiotensin II activity with intravenous saralasin reduced bicar- 
Table I. Hormonal Regulation of Bicarbonate and Water Absorption and cAMP Delivery in Early $\left(S_{1}\right) P C T$

\begin{tabular}{|c|c|c|c|c|c|c|c|c|c|}
\hline \multirow[b]{2}{*}{ Group } & \multirow[b]{2}{*}{$n$} & \multicolumn{3}{|c|}{ Perfused } & \multicolumn{2}{|c|}{ Collected } & \multirow[b]{2}{*}{$J_{\mathrm{v}}$} & \multirow[b]{2}{*}{$J_{\mathrm{HCO}_{3}}$} & \multirow[b]{2}{*}{$T F_{\mathrm{CAMP}} \dot{V}$} \\
\hline & & Length & {$\left[\mathrm{HCO}_{3}^{-}\right]$} & Rate & {$\left[\mathrm{HCO}_{3}^{-}\right]$} & $\dot{V}$ & & & \\
\hline & & $\mathrm{mm}$ & meq/liter & $\mathrm{nl} / \mathrm{min}$ & meq/liter & $\mathrm{nl} / \mathrm{min}$ & $\mathrm{nl} / \mathrm{mm} \cdot \min$ & $\mathrm{peq} / \mathrm{mm} \cdot \mathrm{min}$ & $\mathrm{fmol} / \mathrm{mm} \cdot \mathrm{min}$ \\
\hline Control & \multirow{3}{*}{5} & $0.76 \pm 0.03$ & $24.7 \pm 0.1$ & $29.7 \pm 0.2$ & $18.2 \pm 0.6$ & $26.3 \pm 0.03$ & $4.8 \pm 0.1$ & $344 \pm 10$ & $16.9 \pm 2.0$ \\
\hline Control & & & & $29.7 \pm 0.2$ & $18.0 \pm 0.6$ & $26.1 \pm 0.2$ & $4.8 \pm 0.1$ & $349 \pm 9$ & $17.3 \pm 3$ \\
\hline$P<$ & & & & NS & NS & NS & NS & NS & NS \\
\hline Control & \multirow{3}{*}{5} & $0.74 \pm 0.03$ & $24.2 \pm 0.2$ & $29.8 \pm 0.4$ & $17.8 \pm 0.2$ & $26.2 \pm 0.2$ & $4.9 \pm 0.1$ & $348 \pm 11$ & $17.9 \pm 2.0$ \\
\hline AII & & & & $29.7 \pm 0.1$ & $11.8 \pm 0.6$ & $24.5 \pm 0.3$ & $7.2 \pm 0.4$ & $588 \pm 8$ & $11.7 \pm 1.5$ \\
\hline$P<$ & & & & NS & 0.001 & 0.001 & 0.001 & 0.001 & 0.05 \\
\hline Control & \multirow{3}{*}{5} & $0.76 \pm 0.01$ & $24.4 \pm 0.2$ & $29.9 \pm 0.2$ & $17.5 \pm 0.3$ & $26.5 \pm 0.5$ & $4.4 \pm 0.1$ & $351 \pm 5$ & $18.1 \pm 0.5$ \\
\hline PTH & & & & $29.9 \pm 0.2$ & $21.1 \pm 0.4$ & $27.7 \pm 0.3$ & $2.9 \pm 0.1$ & $194 \pm 12$ & $23.5 \pm 0.9$ \\
\hline$P<$ & & & & NS & 0.001 & 0.001 & 0.001 & 0.001 & 0.001 \\
\hline AII & \multirow{3}{*}{3} & $0.80 \pm 0.3$ & $24.2 \pm 0.4$ & $29.9 \pm 0.2$ & $12.2 \pm 0.2$ & $23.9 \pm 0.6$ & $7.5 \pm 0.3$ & $542 \pm 4$ & $11.9 \pm 0.4$ \\
\hline AII + PTH & & & & $29.8 \pm 0.1$ & $16.4 \pm 0.6$ & $24.1 \pm 0.6$ & $6.5 \pm 0.2$ & $400 \pm 15$ & $16.1 \pm 1.2$ \\
\hline$P<$ & & & & NS & 0.001 & 0.05 & 0.05 & 0.001 & 0.01 \\
\hline PTH & \multirow{3}{*}{3} & $0.77 \pm 0.04$ & $24.8 \pm 0.1$ & $29.8 \pm 0.1$ & $21.4 \pm 0.3$ & $27.5 \pm 0.2$ & $2.9 \pm 0.2$ & $195 \pm 9$ & $24.0 \pm 1.8$ \\
\hline PTH + AII & & & & $29.7 \pm 0.2$ & $17.5 \pm 0.3$ & $22.6 \pm 0.3$ & $9.3 \pm 0.4$ & $444 \pm 14$ & $15.4 \pm 0.8$ \\
\hline$P<$ & & & & NS & 0.001 & 0.001 & 0.001 & 0.001 & 0.005 \\
\hline SAR & \multirow{3}{*}{5} & $0.81 \pm 0.02$ & $24.7 \pm 0.1$ & $29.8 \pm 0.1$ & $21.1 \pm 0.3$ & $26.5 \pm 0.6$ & $3.4 \pm 0.1$ & $204 \pm 8$ & $23.3 \pm 1.6$ \\
\hline $\mathrm{SAR}+\mathrm{PTH}$ & & & & $29.5 \pm 0.1$ & $23.1 \pm 0.3$ & $28.1 \pm 0.1$ & $1.7 \pm 0.1$ & $101 \pm 11$ & $29.1 \pm 1.9$ \\
\hline$P<$ & & & & NS & 0.001 & 0.001 & 0.001 & 0.001 & 0.001 \\
\hline PTX & \multirow{3}{*}{5} & $0.82 \pm 0.02$ & $24.5 \pm 0.2$ & $29.8 \pm 0.3$ & $15.9 \pm 0.1$ & $25.5 \pm 0.1$ & $5.0 \pm 0.2$ & $398 \pm 7$ & $12.4 \pm 0.5$ \\
\hline PTX + AII & & & & $29.9 \pm 0.1$ & $10.0 \pm 0.3$ & $22.9 \pm 0.1$ & $8.4 \pm 0.1$ & $609 \pm 11$ & $9.0 \pm 0.4$ \\
\hline$P<$ & & & & NS & 0.001 & 0.001 & 0.001 & 0.001 & 0.002 \\
\hline PT & \multirow{3}{*}{5} & $0.82 \pm 0.01$ & $24.5 \pm 0.2$ & $29.9 \pm 0.1$ & $19.3 \pm 0.1$ & $26.9 \pm 0.3$ & $3.6 \pm 0.3$ & $261 \pm 4$ & $19.6 \pm 0.4$ \\
\hline PT + AII & & & & $29.9 \pm 0.1$ & $13.2 \pm 0.2$ & $22.7 \pm 0.2$ & $8.8 \pm 0.2$ & $394 \pm 5$ & $15.5 \pm 1.0$ \\
\hline$P<$ & & & & NS & 0.001 & 0.005 & 0.001 & 0.001 & 0.001 \\
\hline Control & \multirow{3}{*}{5} & $0.85 \pm 0.01$ & $24.4 \pm 0.3$ & $29.7 \pm 0.1$ & $17.1 \pm 0.4$ & $25.2 \pm 0.1$ & $5.3 \pm 0.1$ & $344 \pm 9$ & $17.7 \pm 0.8$ \\
\hline AII (luminal) & & & $24.1 \pm 0.2$ & $29.8 \pm 0.1$ & $15.5 \pm 0.3$ & $24.5 \pm 0.2$ & $6.2 \pm 0.3$ & $400 \pm 2$ & $14.1 \pm 0.6$ \\
\hline$P<$ & & & & NS & 0.001 & 0.01 & 0.005 & 0.001 & 0.001 \\
\hline
\end{tabular}

Abbreviations: AII, angiotensin II; SAR, saralasin; $J_{\mathrm{v}}$, water absorption rate; $J_{\mathrm{HCO}}$, bicarbonate absorption rate; $T F_{\mathrm{cAMP}} V$, cAMP delivery rate.

bonate absorption $(204 \pm 8 \mathrm{peq} / \mathrm{mm} \cdot \mathrm{min})$ with a reciprocal rise in tubular fluid cAMP delivery $(23.3 \pm 1.6 \mathrm{fmol} / \mathrm{mm} \cdot \mathrm{min})$ and subsequent PTH administration further changed both parameters $(101 \pm 11 \mathrm{peq} / \mathrm{mm} \cdot \mathrm{min}, P<0.001$, and $29.1 \pm 1.9$ $\mathrm{fmol} / \mathrm{mm} \cdot \mathrm{min}, P<0.001$, respectively). Conversely, reduction of endogenous PTH activity by PTX increased bicarbonate absorption $(398 \pm 7 \mathrm{peq} / \mathrm{mm} \cdot \mathrm{min})$ and diminished cAMP delivery $(12.4 \pm 0.5 \mathrm{fmol} / \mathrm{mm} \cdot \mathrm{min})$, and subsequent angiotensin II administration further changed both $(609 \pm 11 \mathrm{peq} /$ $\mathrm{mm} \cdot \mathrm{min}, P<0.001$, and $9.0 \pm 0.4 \mathrm{fmol} / \mathrm{mm} \cdot \mathrm{min}, P<0.002$, respectively), although not to quite the extent as had obtained in the control condition. Thus, angiotensin II and PTH had opposite but additive effects on $\mathrm{S}_{1}$ PCT bicarbonate absorption over a very large range of hormonal activities of endogenous or exogenous origin. There was an excellent inverse correlation of bicarbonate absorption with tubular fluid cAMP delivery rates.

In most cells studied in which angiotensin II receptor occupancy evokes a decrease in adenylate cyclase activity, an inhibitory $G$ protein $\left(G_{i}\right)$ serves as the coupling mechanism $(13,19,20,24) . G_{i}$ proteins can be inhibited by ADP-ribosylation when exposed to PT. If angiotensin II receptor occupancy stimulated PCT bicarbonate absorption by a $\mathrm{G}_{\mathrm{i}}$-mediated reduction in intracellular cAMP, PT should blunt these angiotensin II responses. This hypothesis was tested by pretreating the animals with PT in vivo according to established protocols $(24,32)$. As shown in Table I, PT pretreatment caused a lower baseline bicarbonate absorption $(261 \pm 4 \mathrm{peq} / \mathrm{mm} \cdot \mathrm{min})$ and higher cAMP delivery $(19.6 \pm 0.4 \mathrm{fmol} / \mathrm{mm} \cdot \mathrm{min})$ than control. The subsequent responses to angiotensin II were attenuated by $\sim 35-45 \%$. As shown in Fig. 3, compared with control values, PT pretreatment blunted both the increment in $S_{1}$ bicarbonate absorption (239 \pm 14 versus $133 \pm 4 \mathrm{peq} / \mathrm{mm} \cdot \mathrm{min}$, $P<0.001)$ and the reduction in cAMP delivery $(-6.2 \pm 0.6$ vs. $-4.1 \pm 0.6 \mathrm{fmol} / \mathrm{mm} \cdot \mathrm{min}, P<0.001)$. These results are consistent with the role of a $G_{i}$ protein in coupling angiotensin II receptor occupancy to reduction of intracellular cAMP and augmentation of tubular acidification.

When all the results of the 72 studies described above were combined as shown in Fig. 4, there was an excellent negative correlation of bicarbonate absorption in the $S_{1}$ PCT with tubular fluid cAMP delivery $(Y=-21.3 X+740, r=0.86, P$ $<0.001$ ).

In the $S_{2} P C T$, qualitatively similar results were found, as 

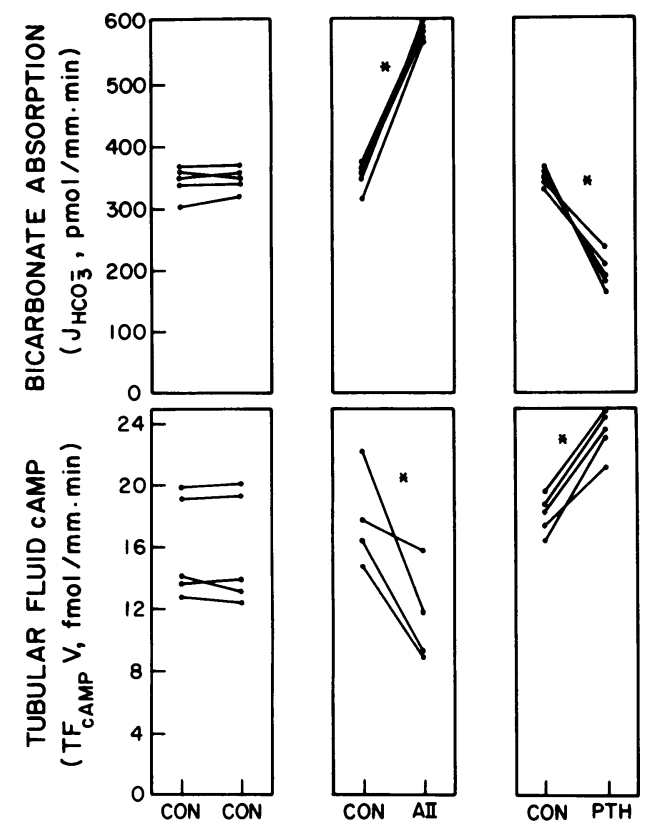

Figure 1. Effects on bicarbonate absorption and tubular fluid cAMP delivery in the $S_{1}$ PCT during (left) persistent time controls (CON), (middle) by intravenous angiotensin II (AII) administration, and (right) by intravenous PTH administration. ${ }^{*} P<0.05$.
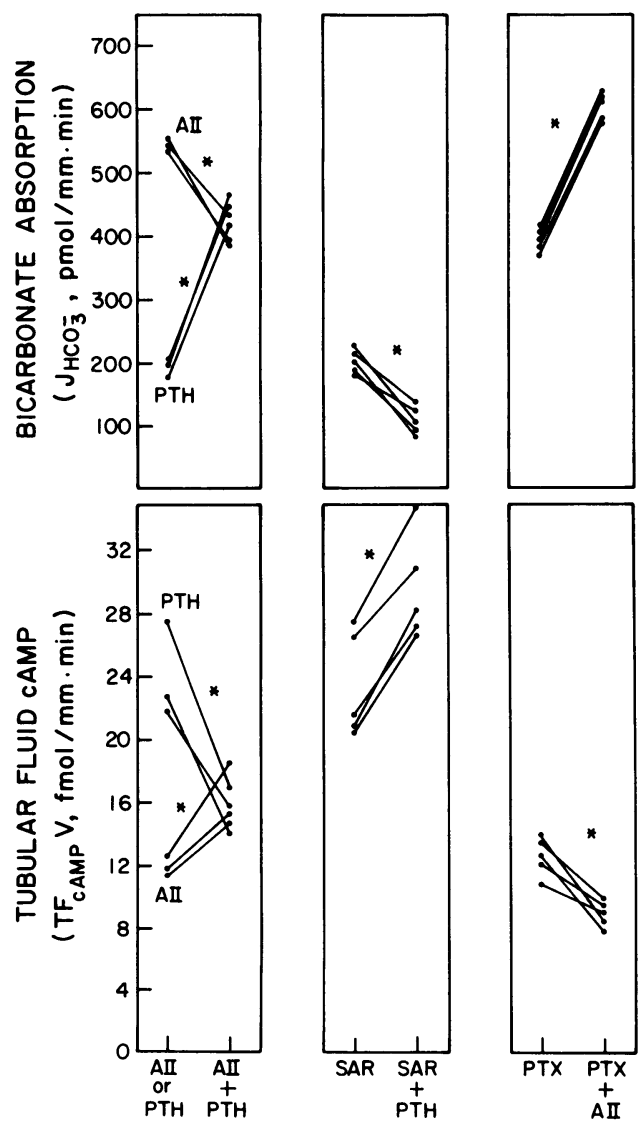

Figure 2. Effects on bicarbonate absorption and tubular fluid cAMP delivery in the $S_{1}$ PCT (left) by intravenous angiotensin II (AII) or by PTH with subsequent administration of both hormones, (middle) by intravenous saralasin with subsequent administration of PTH, and (right) by parathyroidectomy (PTX) with subsequent administration of angiotensin II. ${ }^{*} P<0.01$.

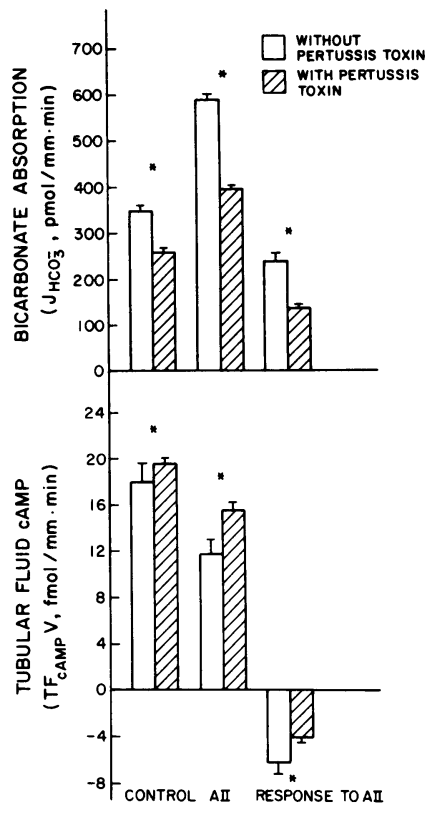

Figure 3. Effects of PT pretreatment on the response of $S_{1}$ PCT bicarbonate absorptive and tubular fluid cAMP delivery rates to intravenous angiotensin II (AII). ${ }^{*} P<0.001$

shown in Table II and Fig. 5. Bicarbonate absorption in the $\mathrm{S}_{2}$ PCT also inversely correlated with cAMP delivery $(Y$ $=-21.1 X+300, r=0.87, P<0.001)$. The absolute magnitude of the hormonal regulation of bicarbonate absorption and cAMP delivery was much less in the $S_{2}$ compared with the $S_{1}$ segment, consistent with the diminished angiotensin II receptor density previously demonstrated in the $\mathrm{S}_{2}$ PCT (3).

The results in Figs. 4 and 5 support the hypothesis that angiotensin II controls proximal bicarbonate absorption by lowering intracellular cAMP. However, this negative correlation does not necessarily establish causality and two further lines of evidence were therefore pursued. First, to rule out a

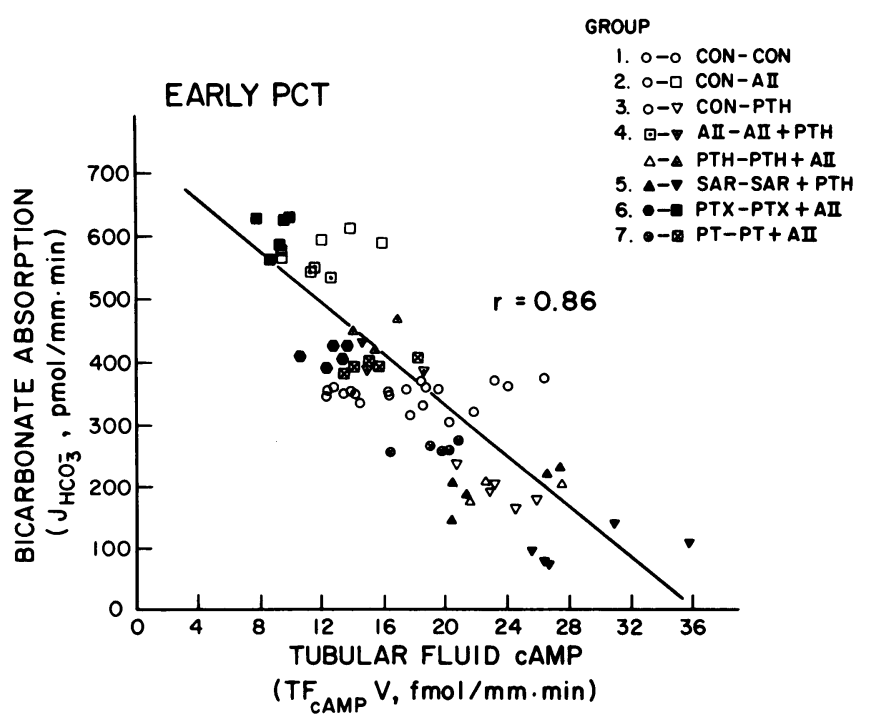

Figure 4. Relationship of bicarbonate absorption to tubular fluid cAMP delivery in the early, $S_{1}$ PCT for groups depicted in Figs. 1-3 and Table 1. Group abbreviations: control (CON), angiotensin (AII), PTH, saralasin (SAR), PTX, and PT pretreatment (PT). Regression equation for the 72 experimental points was $Y=-21.3 X+740, r$ $=0.86, P<0.001$. 
Table II. Hormonal Regulation of Bicarbonate and Water Absorption and cAMP Delivery in Late $\left(S_{2}\right) P C T$

\begin{tabular}{|c|c|c|c|c|c|c|c|c|c|}
\hline \multirow[b]{2}{*}{ Group } & \multirow[b]{2}{*}{$n$} & \multicolumn{3}{|c|}{ Perfused } & \multicolumn{2}{|c|}{ Collected } & \multirow[b]{2}{*}{$J_{\mathrm{v}}$} & \multirow[b]{2}{*}{$J_{\mathrm{HCO}}$} & \multirow[b]{2}{*}{$T F_{\text {сAMP }} \dot{V}$} \\
\hline & & Length & {$\left[\mathrm{HCO}_{3}^{-}\right]$} & Rate & {$\left[\mathrm{HCO}_{3}^{-}\right]$} & $\dot{V}$ & & & \\
\hline & & $m m$ & meq/liter & $n l / m i n$ & meq/liter & $n l / \min$ & $\mathrm{nl} / \mathrm{mm} \cdot \min$ & $\mathrm{peq} / \mathrm{mm} \cdot \mathrm{min}$ & $\mathrm{fmol} / \mathrm{mm} \cdot \mathrm{min}$ \\
\hline Control & \multirow{3}{*}{5} & $2.21 \pm 0.03$ & $24.7 \pm 0.1$ & $29.8 \pm 0.1$ & $11.5 \pm 0.3$ & $24.0 \pm 0.1$ & $2.6 \pm 0.1$ & $208 \pm 2$ & $4.0 \pm 0.3$ \\
\hline Control & & & & $29.8 \pm 0.1$ & $11.2 \pm 0.2$ & $24.1 \pm 0.1$ & $2.6 \pm 0.1$ & $211 \pm 2$ & $3.6 \pm 0.4$ \\
\hline$P<$ & & & & NS & NS & NS & NS & NS & NS \\
\hline Control & \multirow{3}{*}{5} & $2.25 \pm 0.02$ & $24.2 \pm 0.2$ & $29.8 \pm 0.1$ & $10.8 \pm 0.4$ & $23.8 \pm 0.1$ & $2.7 \pm 0.1$ & $207 \pm 3$ & $4.3 \pm 0.2$ \\
\hline AII & & & & $29.9 \pm 0.1$ & $9.3 \pm 0.3$ & $21.7 \pm 0.1$ & $3.6 \pm 0.1$ & $231 \pm 2$ & $3.2 \pm 0.2$ \\
\hline$P<$ & & & & NS & 0.001 & 0.001 & 0.001 & 0.001 & 0.001 \\
\hline Control & \multirow{3}{*}{5} & $2.25 \pm 0.02$ & $24.4 \pm 0.2$ & $29.9 \pm 0.3$ & $11.0 \pm 0.3$ & $23.8 \pm 0.1$ & $2.7 \pm 0.4$ & $209 \pm 2$ & $4.8 \pm 0.1$ \\
\hline PTH & & & & $29.9 \pm 0.2$ & $13.8 \pm 0.3$ & $24.8 \pm 0.4$ & $2.3 \pm 0.1$ & $173 \pm 2$ & $6.2 \pm 0.3$ \\
\hline$P<$ & & & & NS & 0.001 & 0.001 & 0.001 & 0.001 & 0.005 \\
\hline AII & \multirow{3}{*}{3} & $2.14 \pm 0.07$ & $24.2 \pm 0.4$ & $29.9 \pm 0.6$ & $10.0 \pm 0.5$ & $21.9 \pm 0.2$ & $3.7 \pm 0.2$ & $235 \pm 4$ & $3.8 \pm 0.2$ \\
\hline AII + PTH & & & & $29.7 \pm 0.3$ & $11.8 \pm 0.6$ & $22.3 \pm 0.3$ & $3.4 \pm 0.2$ & $211 \pm 1$ & $4.8 \pm 0.5$ \\
\hline$P<$ & & & & NS & 0.02 & 0.001 & 0.001 & 0.001 & 0.05 \\
\hline PTH & \multirow{3}{*}{3} & $2.21 \pm 0.02$ & $24.8 \pm 0.1$ & $29.6 \pm 0.3$ & $13.5 \pm 0.2$ & $24.9 \pm 0.1$ & $2.3 \pm 0.1$ & $179 \pm 3$ & $5.7 \pm 0.3$ \\
\hline PTH + AII & & & & $29.7 \pm 0.3$ & $11.5 \pm 0.5$ & $21.2 \pm 0.3$ & $3.9 \pm 0.1$ & $223 \pm 2$ & $4.0 \pm 0.1$ \\
\hline$P<$ & & & & NS & 0.005 & 0.001 & 0.001 & 0.001 & 0.01 \\
\hline SAR & \multirow{3}{*}{5} & $2.36 \pm 0.02$ & $24.7 \pm 0.1$ & $29.5 \pm 0.1$ & $12.4 \pm 0.2$ & $26.1 \pm 0.2$ & $1.5 \pm 0.1$ & $172 \pm 3$ & $5.4 \pm 0.1$ \\
\hline SAR + PTH & & & & $29.6 \pm 0.1$ & $15.8 \pm 0.5$ & $27.0 \pm 0.2$ & $1.1 \pm 0.1$ & $130 \pm 6$ & $7.2 \pm 0.2$ \\
\hline$P<$ & & & & NS & 0.001 & 0.001 & 0.001 & 0.001 & 0.001 \\
\hline PTX & \multirow{3}{*}{5} & $2.24 \pm 0.03$ & $24.5 \pm 0.2$ & $29.9 \pm 0.1$ & $10.2 \pm 0.3$ & $22.7 \pm 0.2$ & $3.2 \pm 0.1$ & $224 \pm 3$ & $3.4 \pm 0.1$ \\
\hline PTX + AII & & & & $29.9 \pm 0.1$ & $8.7 \pm 0.4$ & $21.2 \pm 0.1$ & $3.9 \pm 0.1$ & $245 \pm 3$ & $2.5 \pm 0.1$ \\
\hline$P<$ & & & & NS & 0.001 & 0.001 & 0.001 & 0.001 & 0.001 \\
\hline PT & \multirow{3}{*}{5} & $2.27 \pm 0.02$ & $24.5 \pm 0.2$ & $29.8 \pm 0.1$ & $13.2 \pm 0.2$ & $25.6 \pm 0.2$ & $1.8 \pm 0.1$ & $175 \pm 3$ & $5.1 \pm 0.1$ \\
\hline PT + AII & & & & $29.8 \pm 0.1$ & $11.7 \pm 0.2$ & $25.0 \pm 0.5$ & $2.2 \pm 0.2$ & $194 \pm 6$ & $4.4 \pm 0.1$ \\
\hline$P<$ & & & & NS & 0.001 & 0.05 & 0.05 & 0.001 & 0.005 \\
\hline Control & \multirow{3}{*}{5} & $2.22 \pm 0.02$ & $24.4 \pm 0.3$ & $29.8 \pm 0.2$ & $11.4 \pm 0.6$ & $23.8 \pm 0.1$ & $2.7 \pm 0.1$ & $207 \pm 4$ & $4.4 \pm 0.1$ \\
\hline AII (luminal) & & & $24.1 \pm 0.2$ & $29.8 \pm 0.1$ & $9.8 \pm 0.5$ & $23.1 \pm 0.3$ & $3.0 \pm 0.1$ & $222 \pm 4$ & $4.0 \pm 0.1$ \\
\hline$P<$ & & & & NS & 0.001 & 0.05 & 0.05 & 0.01 & 0.001 \\
\hline
\end{tabular}

See Table I for abbreviations.

nonspecific interaction between the two parameters, we used a nonhormonal regulator of proximal bicarbonate absorption to verify that bicarbonate transport could be changed without affecting cAMP delivery. Second, it was necessary to demonstrate that clamping of intracellular cAMP, by exogenous

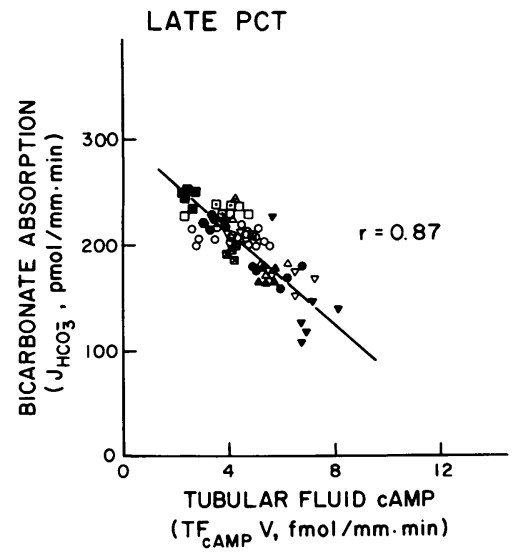

Figure 5. Relationship of bicarbonate absorption to tubular fluid cAMP delivery in the late, $S_{2}$ PCT for groups depicted in Table II.

The same symbols are used to designate groups as in Fig. 4. Regression equation for the 72 experimental points was $Y=-21.1 X$ $+300, r=0.87, P$ $<0.001$.
cAMP administration, prevented the transport response to angiotensin II.

To show that a primary stimulant of bicarbonate absorption, one that did not affect hormone signaling processes, increased transport without altering cAMP delivery, we raised luminal perfusion rate from 30 to $45 \mathrm{nl} / \mathrm{min}$ (30). This increment in luminal perfusion rate markedly increased $S_{1}$ PCT bicarbonate absorption ( $357 \pm 9$ to $500 \pm 13 \mathrm{peq} / \mathrm{mm} \cdot \mathrm{min}, P$ $<0.001$ ), as previously reported (30), but was without effect on cAMP delivery $(18.3 \pm 0.8$ to $18.5 \pm 1.0 \mathrm{fmol} / \mathrm{mm} \cdot \mathrm{min}, \mathrm{NS})$. The same results were found in the $S_{2}$ PCT (207 \pm 6 to $236 \pm 8$ $\mathrm{peq} / \mathrm{mm} \cdot \mathrm{min}, P<0.001$, and $4.6 \pm 0.1$ to $4.3 \pm 0.2 \mathrm{fmol} /$ $\mathrm{mm} \cdot \mathrm{min}$, NS, respectively).

The data obtained by luminal perfusion using a permeable form of cAMP, dibutyryl cAMP, are shown in Table III and Fig. 6. Luminal perfusion with dibutyryl cGMP was also examined, as a control for any nonspecific effects attributable to the dibutyryl moiety. Compared with controls without cyclic nucleotide, dibutyryl cGMP did not significantly alter baseline bicarbonate absorption nor the angiotensin II absorptive response in the $S_{1}$ PCT $(159 \pm 7 \mathrm{peq} / \mathrm{mm} \cdot \mathrm{min})$. However, in the presence of dibutyryl cAMP, the baseline $S_{1}$ PCT bicarbonate 
Table III. Effect of Luminal cAMP and cGMP on the PCT Transport Response to Angiotensin II

\begin{tabular}{|c|c|c|c|c|c|c|c|c|}
\hline \multirow[b]{2}{*}{ Group } & \multirow[b]{2}{*}{$n$} & \multicolumn{3}{|c|}{ Perfused } & \multicolumn{2}{|c|}{ Collected } & \multirow[b]{2}{*}{$J_{\mathrm{v}}$} & \multirow[b]{2}{*}{$J_{\mathrm{HCOS}}$} \\
\hline & & Length & {$\left[\mathrm{HCO}_{3}^{-}\right]$} & Rate & {$\left[\mathrm{HCO}_{3}^{-}\right]$} & $\dot{V}$ & & \\
\hline & & $m m$ & meq/liter & $n l / m i n$ & meq/liter & $n l / m i n$ & $\mathrm{nl} / \mathrm{mm} \cdot \min$ & $\mathrm{peq} / \mathrm{mm} \cdot \min$ \\
\hline \multicolumn{9}{|l|}{ Early PCT } \\
\hline Dibutyryl cAMP & 5 & $0.80 \pm 0.02$ & $24.7 \pm 0.1$ & $29.9 \pm 0.1$ & $20.5 \pm 0.5$ & $27.9 \pm 0.1$ & $2.5 \pm 0.2$ & $199 \pm 8$ \\
\hline Dibutyryl cAMP + AII & & & & $29.9 \pm 0.1$ & $20.7 \pm 0.4$ & $27.9 \pm 0.1$ & $2.5 \pm 0.2$ & $197 \pm 7$ \\
\hline$P<$ & & & & NS & NS & NS & NS & NS \\
\hline Dibutyryl cGMP & 5 & $0.78 \pm 0.01$ & $24.5 \pm 0.2$ & $29.7 \pm 0.1$ & $17.6 \pm 0.1$ & $25.8 \pm 0.1$ & $4.9 \pm 0.1$ & $348 \pm 7$ \\
\hline Dibutyryl cGMP + AII & & & & $29.7 \pm 0.1$ & $13.8 \pm 0.3$ & $24.0 \pm 0.1$ & $7.3 \pm 0.2$ & $507 \pm 11$ \\
\hline$P<$ & & & & NS & 0.001 & 0.001 & 0.001 & 0.001 \\
\hline \multicolumn{9}{|l|}{ Late PCT } \\
\hline Dibutyryl cAMP & 5 & $2.20 \pm 0.03$ & & $29.9 \pm 0.1$ & $13.6 \pm 0.2$ & $25.0 \pm 0.1$ & $2.2 \pm 0.1$ & $181 \pm 3$ \\
\hline Dibutyryl cAMP + AII & & & & $29.9 \pm 0.1$ & $13.7 \pm 0.2$ & $25.0 \pm 0.1$ & $2.2 \pm 0.1$ & $180 \pm 2$ \\
\hline$P<$ & & & & NS & NS & NS & NS & NS \\
\hline Dibutyryl cGMP & 5 & $2.21 \pm 0.03$ & & $29.8 \pm 0.1$ & $11.3 \pm 0.2$ & $23.5 \pm 0.1$ & $2.8 \pm 0.1$ & $210 \pm 3$ \\
\hline Dibutyryl cGMP + AII & & & & $29.7 \pm 0.1$ & $9.8 \pm 0.2$ & $21.6 \pm 0.1$ & $3.7 \pm 0.1$ & $234 \pm 1$ \\
\hline$P<$ & & & & NS & 0.001 & 0.001 & 0.001 & 0.001 \\
\hline
\end{tabular}

See Table I for abbreviations.

absorptive response rate was substantially lower than the control value and the response to angiotensin II was obliterated $(-4 \pm 5 \mathrm{peq} / \mathrm{mm} \cdot \mathrm{min})$.

The results described thus far examined the biochemicalphysiologic coupling evoked by basolateral receptor occupancy in response to intravenous hormones. Angiotensin II receptors also exist on the luminal membrane and can evoke a physiologic response $(3,25)$. We therefore felt it would be of interest to examine whether luminal angiotensin II stimulated bicarbonate absorption by reducing cAMP. As shown in Tables I and II and Fig. 7, the bicarbonate absorptive response in the $S_{1}$ PCT to luminal angiotensin II $\left(10^{-12} \mathrm{M}\right)$ was somewhat less (an increment of $55 \pm 9 \mathrm{peq} / \mathrm{mm} \cdot \mathrm{min}$ ) than when angiotensin II had been given intravenously, as previously reported (3). Luminal angiotensin II also depressed cAMP delivery in the $S_{1} P C T$ (by $-3.6 \pm 0.4 \mathrm{fmol} / \mathrm{mm} \cdot \mathrm{min}$ ). The quantitative relationship between the increment in bicarbonate absorption and the depression in cAMP delivery by luminal angiotensin II was similar to that previously described for basolateral angiotensin II (Figs. 4 and 5), suggesting similarity between luminal and basolateral signaling mechanisms.

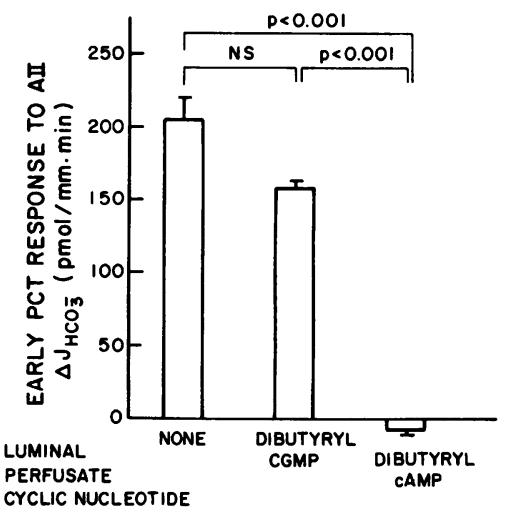

Figure 6. Effect on the angiotensin-induced stimulation of early, $S_{1}$ PCT bicarbonate reabsorption when no cyclic nucleotide was present in the luminal perfusate (from control studies in the present and previous series [2]), compared with the response when $10^{-5} \mathrm{M}$ dibutyryl CGMP or $10^{-5} \mathrm{M}$ dibutyryl cAMP was added to the luminal perfusate.

\section{Discussion}

Angiotensin II was recently shown to exert powerful, direct epithelial cell receptor-mediated control of $S_{1}$ PCT bicarbonate absorption $(2,3)$. This modulation of acidification was amiloride sensitive, implicating the $\mathrm{Na}^{+} / \mathrm{H}^{+}$antiporter as a participant in the transport regulation (3). The present results provide evidence that the signal transduction system whereby angiotensin II controls epithelial cell transport is via diminution in intracellular cAMP.

The ability for angiotensin II to depress adenylate cyclase activity and intracellular cAMP level has been described in many tissues $(11,12)$, including liver (13-15), aorta (16), adrenal cortex $(17,18)$, pituitary (19), and testis (20). In the kidney, this signaling process has been shown in cortical homogenates (21), glomeruli $(22,23)$, juxtaglomerular apparatus (24), tubule suspensions (23), and proximal cells in culture (25). In some of these studies, the necessary intermediation of a $G_{i}$ protein was demonstrated by showing that the decrement in cAMP evoked by angiotensin II was sensitive to pertussis toxin $(13,19,20,24)$. To date, however, no renal epithelial cell function has been linked to this intracellular signaling system used by angiotensin II.

These studies provide the initial evidence in vivo that the powerful control of $S_{1}$ PCT bicarbonate absorption by angiotensin II might occur through derepression of cAMP-mediated inhibition of the $\mathrm{Na}^{+} / \mathrm{H}^{+}$antiporter. The PT sensitivity of the $S_{1}$ PCT transport effects of angiotensin II (Fig. 3) implied that a $G_{i}$ protein couples the angiotensin II receptor to the inhibition of adenylate cyclase. Effects on other PT-sensitive G proteins cannot be excluded, however. The PTH receptor, which is coupled via $\mathbf{a ~}_{\mathrm{s}}$ protein to activate adenylate cyclase, caused the expected opposite effects, an increase in intracellular cAMP and inhibition of bicarbonate transport $(26,27)$. These studies are the first to demonstrate that endogenous and exogenous PTH can markedly affect $S_{1}$ PCT transport. 

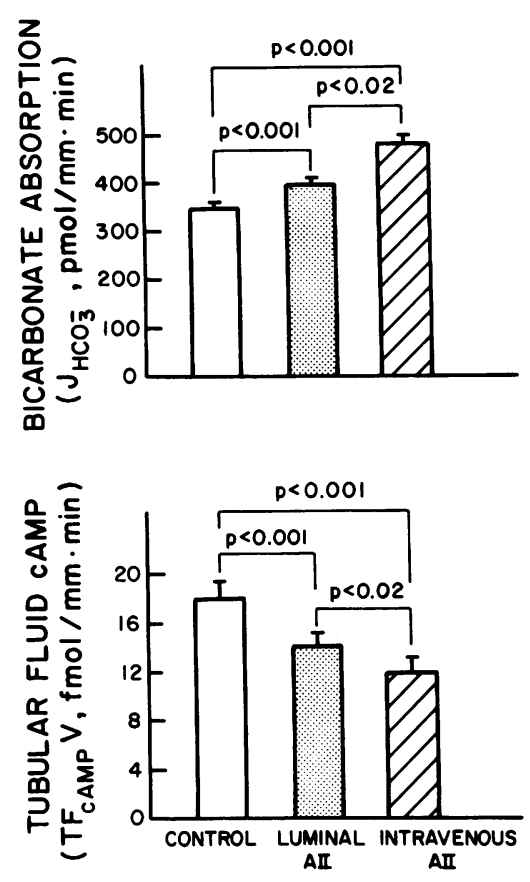

Figure 7. Comparison of control rates of bicarbonate absorption and tubular fluid cAMP delivery in the $S_{1}$ PCT to those when $10^{-12} \mathrm{M}$ angiotensin II was present in the luminal perfusate (stippled bar) or when angiotensin II was administered intravenously (striped bar).

Bicarbonate absorption was associated with reciprocal changes in cAMP over quite a large range (Figs. 4 and 5). The span of $S_{1}$ PCT bicarbonate absorption affected by hormonally induced changes in intracellular cAMP concentration was from 100 to $600 \mathrm{peq} / \mathrm{mm} \cdot \mathrm{min}$ (Fig. 4). This magnitude of bicarbonate absorption associated with changes in cAMP, 500 $\mathrm{peq} / \mathrm{mm} \cdot \mathrm{min}$, represents $\geq 80 \%$ of the hydrogen ion secretory capacity in the $S_{1}$ PCT (30). Hydrogen ion secretion by the $S_{1}$ PCT is normally responsible for reabsorbing at least half (500-600 peq/min) of the filtered bicarbonate load $(1,000$ $\mathrm{peq} / \mathrm{min}$ ) (1). Thus, a substantial portion (approaching half) of total renal acidification is potentially sensitive to hormonal modulation via cAMP.

Two further lines of evidence were obtained to support the contention that reduction in intracellular cAMP was causally related to the stimulation of acidification induced by angiotensin II. First, exogenous dibutyryl cAMP, to clamp the intracellular cAMP concentration, prevented angiotensin II from stimulating bicarbonate absorption (Table III and Fig. 6). Second, a change in luminal flow rate, a nonhormonal modulator of bicarbonate absorption in the PCT (30), did not affect cAMP delivery.

Fig. 8 depicts a simple model for hormonal control of bicarbonate reabsorption in the $S_{1} P C T$. In this scheme, the angiotensin II receptor (and perhaps others) inhibits adenylate cyclase via $\mathrm{G}_{\mathrm{i}}$ protein(s), while the PTH receptor (and perhaps others) stimulates adenylate cyclase via $G_{s}$ protein(s). Intracellular cAMP is the final common pathway in the transport regulation; cAMP presumably activates a cAMP-dependent protein kinase to directly inhibit the $\mathrm{Na}^{+} / \mathrm{H}^{+}$antiporter (25).

A dual, positive-negative (ying-yang) control system is envisioned in this model in which increasing $G_{i}$ activity is functionally equivalent to decreasing $G_{s}$ activity and vice versa. For instance, similar changes in bicarbonate absorption and cAMP delivery were induced by either angiotensin II or PTX (Fig. 2). The converse changes were induced by either saralasin or PTH (Fig. 2). When angiotensin II and PTH were added together,

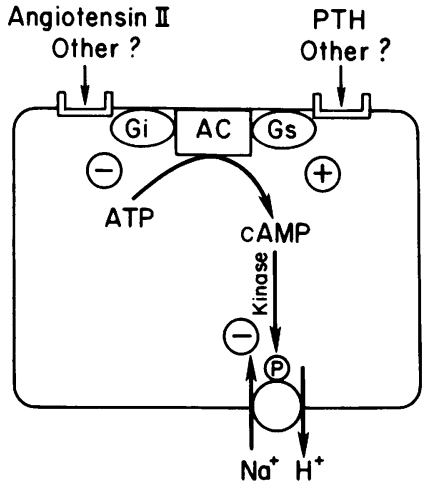

Figure 8. Model for hormonal regulation of $S_{1}$ proximal bicarbonate reabsorption. The angiotensin II receptor is coupled to an inhibitory $G$ protein $\left(G_{i}\right)$ that diminishes adenylate cyclase (AC) activity and depresses the level of intracellular cAMP. cAMP, activating a cAMP-dependent protein kinase, acts to inhibit the $\mathrm{Na}^{+} / \mathrm{H}^{+}$antiporter. Thus, angiotensin II serves to derepress the antiporter and thereby stimulates bicarbonate absorption. The PTH receptor is coupled to a stimulatory $G$ protein $\left(G_{s}\right)$ and has the opposite effects, to activate adenylate cyclase and increase intracellular cAMP and thereby to depress $\mathrm{Na}^{+} / \mathrm{H}^{+}$antiporter activity and bicarbonate absorption.

there was virtual cancellation of each other's biochemical and physiological actions (Fig. 2). These results suggested endogenous levels of both angiotensin II and PTH exert tonic effects on PCT cAMP levels and bicarbonate absorption. Furthermore, upward and downward changes in the activities of both hormones can potentially lead to additive functional transport changes. Further studies are required to identify the role of cAMP in altering bicarbonate reabsorption under physiologic conditions. Although the range of systemic angiotensin II concentrations used in these studies was within a physiologic range and without effect on systemic or glomerular hemodynamics $(2,3)$, the range of PTH concentrations examined was not physiologic.

These in vivo results are consistent with the signaling scheme depicted in Fig. 8, though clearly the model is overly simplistic and conjectural in many respects. Many other neurotransmitters and hormones, such as muscarinic cholinergic agents, alpha ${ }_{2}$-adrenergic agents, adenosine ${ }_{1}$ agonists, dopamine, and opiates have been reported to decrease adenylate cylase activity in other cell types $(11,12)$. If receptors for these substances exist in the PCT, they might also regulate electrolyte transport.

Angiotensin II is a relatively unique hormone in the kidney in possessing functionally active receptors on both the luminal and basolateral aspects of the epithelial cell $(3,25)$. The results shown in Fig. 7 suggest that reduction in intracellular cAMP may also be the mechanism for transducing the $S_{1}$ PCT transport stimulation when angiotensin II is present in the lumen as it is when exposed to the basolateral surface.

The possibility is not excluded that angiotensin II uses other signal transduction mechanism(s) besides reduction in intracellular cAMP to affect PCT bicarbonate absorption. For instance, if angiotensin II caused phosphatidylinositol breakdown in the $S_{1}$ PCT as it does in vascular smooth muscle, the subsequent rise in intracellular calcium and activation of protein kinase $\mathrm{C}$ might be expected to stimulate the $\mathrm{Na}^{+} / \mathrm{H}^{+}$exchanger $(4,5)$. In PCT cells, angiotensin II can increase phosphatidylinositol breakdown (6) and, in very high concentrations $\left(10^{-8}-10^{-5} \mathrm{M}\right)$, can raise intracellular calcium $(7,8)$, but correlative changes in ion transport have not been reported. Phorbol ester-induced activation of protein kinase $C$ caused an amiloride-sensitive alkalinization in canine proximal cells, 
suggesting stimulation of the $\mathrm{Na}^{+} / \mathrm{H}^{+}$exchanger (9), but perfusion of phorbol ester inhibited bicarbonate absorption in the rabbit $S_{2}$ PCT in vitro (10). In preliminary studies in the rat $S_{1}$ PCT in vivo, perfusion of phorbol ester enhanced bicarbonate absorption, but did not prevent further stimulation by angiotensin II (Liu, F.-Y., and M. G. Cogan, unpublished observations).

Angiotensin II has also been reported to stimulate guanylate cyclase in renal cells (36). However, the PCT lacks particulate guanylate cyclase (37) and does not produce cGMP in vivo under the influence of endogenous angiotensin II (38). Exogenous administration of dibutyryl cGMP had no effect on PCT bicarbonate absorption and failed to prevent the angiotensin II-induced stimulation of proximal bicarbonate reabsorption (Table III and Fig. 6). More information is needed to clarify the possible interaction of other angiotensin II signaling systems with the cAMP reduction mechanism in controlling renal epithelial cell transport.

In conclusion, the stimulation of $S_{1}$ PCT bicarbonate $a b-$ sorption by angiotensin II was correlated with a decline in tubular fluid cAMP delivery. PTH had the opposite effects. The angiotensin-induced transport stimulation was attenuated by PT, and was abolished by exogenous dibutyryl cAMP. The results are consistent with a model in which angiotensin II stimulates early proximal bicarbonate absorption by a $\mathrm{G}_{\mathrm{i}}$-mediated depression in intracellular cAMP.

\section{Acknowledgments}

These studies were supported in part by a grant (DK-37423) from the National Institute of Diabetes and Digestive and Kidney Diseases and by an Established Investigator Award from the American Heart Association.

\section{References}

1. Liu, F.-Y., and M. G. Cogan. 1986. Axial heterogeneity of bicarbonate, chloride and water transport in the rat proximal convoluted tubule. Effects of change in luminal flow rate and of alkalemia. J. Clin. Invest. 78:1547-1557.

2. Liu, F.-Y., and M. G. Cogan. 1987. Angiotensin II: a potent regulator of acidification in the rat early proximal convoluted tubule. J. Clin. Invest. 80:272-275.

3. Liu, F.-Y., and M. G. Cogan. 1988. Angiotensin II stimulation of hydrogen ion secretion in the rat early proximal tubule. Modes of action, mechanism, and kinetics. J. Clin. Invest. 82:601-607.

4. Berk, B. C., M. S. Aronow, T. A. Brock, E. Cragoe, Jr., M. A. Gimbrone, Jr., and R. W. Alexander. 1987. Angiotensin II-stimulated $\mathrm{Na}^{+} / \mathrm{H}^{+}$exchange in cultured vascular smooth muscle cells. Evidence for protein kinase C-dependent and -independent pathways. J. Biol. Chem. 262:5057-5064.

5. Hatori, N., B. P. Fine, A. Nakamura, E. Cragoe, Jr., and A. Aviv. 1987. Angiotensin II effect on cytosolic pH in cultured rat vascular smooth muscle cells. J. Biol. Chem. 262:5073-5078.

6. Kaloyanides, G. J., L. Ramsammy, and C. Josepovitz. 1988. Gentamicin induces a generalized disruption of the phosphatidylinositol (PI) cascade in primary cultures of rabbit proximal tubular cells (PCRPTC). Kidney Int. 33:360.

7. Dominguez, J. H., K. W. Snowdowne, C. C. Freudenrich, T. Brown, and A. B. Borle. 1987. Intracellular messenger for action of angiotensin II on fluid transport in rabbit proximal tubule. Am. J. Physiol. 252 (Renal Fluid Electrolyte Physiol. 21):F423-F428.

8. Welsh, C., G. Dubyak, and J. G. Douglas. 1988. Relationship between phospholipase $C$ activation and prostaglandin $E_{2}$ and cyclic adenosine monophosphate production in rabbit tubular epithelial cells. Effects of angiotensin, bradykinin, and arginine vasopressin. $J$. Clin. Invest. 81:710-719.

9. Mellas, J., and M. R. Hammerman. 1986. Phorbol ester-induced alkalinization of canine renal proximal tubular cells. Am. J. Physiol. 250 (Renal Fluid Electrolyte Physiol. 19):F451-F459.

10. Baum, M., and S. R. Hays. 1988. Phorbol myristate acetate and dioctanoylglycerol inhibit transport in rabbit proximal convoluted tubule. Am. J. Physiol. 254 (Renal Fluid Electrolyte Physiol. 23):F9-F14.

11. Jakobs, K. H., K. Aktories, and G. Schultz. 1981. Inhibition of adenylate cyclase by hormones and neurotransmitters. Adv. Cyclic Nucleotide Res. 14:173-187.

12. Limbird, L. E. 1988. Receptors linked to inhibition of adenylate cyclase: additional signaling mechanisms. FASEB (Fed. Am. Soc. Exp. Biol.) J. 2:2686-2695.

13. Pobiner, B. F., E. L. Hewlett, and J. C. Garrison. 1985. Role of $\mathrm{N}_{\mathrm{i}}$ in coupling angiotensin receptors to inhibition of adenylate cyclase in hepatyocytes. J. Biol. Chem. 260:16200-16209.

14. Crane, J. K., C. P. Campanile, and J. C. Garrison. 1982. The hepatic angiotensin II receptor. II. Effect of guanine nucleotides and interaction with cyclic AMP production. J. Biol. Chem. 257:49594965.

15. Jard, S., B. Cantau, and K. H. Jakobs. 1981. Angiotensin II and alpha-adrenergic agonists inhibit rat liver adenylate cyclase. J. Biol. Chem. 256:2603-2606.

16. Anand-Srivastava, M. B. 1983. Angiotensin II receptors negatively coupled to adenylate cyclase in rat aorta. Biochem. Biophys. Res. Commun. 117:420-428.

17. Marie, J., and S. Jard. 1983. Angiotensin II inhibits adenylate cyclase from adrenal cortex glomerulosa zone. FEBS (Fed. Eur. Biochem. Soc.) Lett. 159:97-101.

18. Woodcock, E. A., and C. I. Johnston. 1984. Inhibition of adenylate cyclase in rat adrenal glomerulosa cells by angiotensin II. Endocrinology. 115:337-341.

19. Enjalbert, A., F. Sladeczek, G. Guillon, P. Bertrand, C. Shu, J. Epelbaum, A. Garcia-Sainz, S. Jard, C. Lombard, C. Kordon, and J. Bockaert. 1986. Angiotensin II and dopamine modulate both cAMP and inositol phosphate productions in anterior pituitary cells. Involvement in prolactin secretion. J. Biol. Chem. 261:4071-4075, 1986.

20. Khanum, A., and M. L. Dufau. 1988. Angiotensin II receptors and inhibitory actions in Leydig cells. J. Biol. Chem. 263:5070-5074.

21. Woodcock, E. A., and C. I. Johnston. 1982. Inhibition of adenylate cyclase by angiotensin II in rat renal cortex. Endocrinology. 111:1687-1691.

22. Douglas, J. G. 1987. Subpressor infusions of angiotensin II alter glomerular binding, prostaglandin $\mathrm{E}_{2}$, and cyclic AMP production. Hypertension (Baltimore). 9(Suppl. III):III-49-III-56.

23. Torres, V. E., T. E. Northrup, R. M. Edwards, S. V. Shah, and T. P. Dousa. 1978. Modulation of cyclic nucleotides in isolated rat glomeruli. Role of histamine, carbamylcholine, parathyroid hormone, and angiotensin-II. J. Clin. Invest. 62:1334-1343.

24. Hackenthal, E., K. Aktories, and K. H. Jakobs. 1985. Pertussis toxin attenuates angiotensin II-induced vasoconstriction and inhibition of renin release. Mol. Cell. Endocrinol. 42:113-117.

25. Douglas, J. G. 1987. Angiotensin receptor subtypes of the kidney cortex. Am. J. Physiol. 253 (Renal Fluid Electrolyte Physiol. 22):F1-F7.

26. Kahn, A. M., G. M. Dolson, M. K. Hise, S. C. Bennett, and E. J. Weinman. 1985. Parathyroid hormone and dibutyryl cAMP inhibit $\mathrm{Na}^{+} / \mathrm{H}^{+}$exchange in renal brush border vesicles. Am. J. Physiol. 248 (Renal Fluid Electrolyte Physiol.):F212-F218.

27. McKinney, T. D., and P. Myers. 1980. Bicarbonate transport by proximal tubules: Effect of parathyroid hormone and dibutyryl cyclic AMP. Am. J. Physiol. 238 (Renal Fluid Electrolyte Physiol. 7):F166-F174.

28. Barber, R., and R. W. Butcher. 1983. The egress of cyclic AMP from metazoan cells. Adv. Cyclic Nucleotide Res. 15:119-138.

29. Strewler, G. J. 1984. Release of cAMP from a renal epithelial cell line. Am. J. Physiol. 246 (Cell Physiol. 15):C224-C230. 
30. Liu, F.-Y., and M. G. Cogan. 1988. Flow-dependence of bicarbonate transport in the early $\left(\mathrm{S}_{1}\right)$ proximal convoluted tubule. Am. J. Physiol. 254 (Fluid Electrolyte Physiol. 23):F851-F855.

31. Maunsbach, A. B. 1966. Observations on the segmentation of the proximal tubule in the rat kidney. J. Ultrastruct. Res. 16:239-258.

32. Rossi, N. F., P. C. Churchill, and M. C. Churchill. 1987. Pertussis toxin reverses adenosine receptor-mediated inhibition of renin secretion in rat renal cortical slices. Life Sci. 40:481-487.

33. Blonde, L., R. E. Wehmann, and A. L. Steiner. 1974. Plasma clearance rates and renal clearance of ${ }^{3} \mathrm{H}$-labeled cyclic AMP and ${ }^{3} \mathrm{H}$-labeled cyclic GMP in the dog. J. Clin. Invest. 53:163-172.

34. Broadus, A. E., N. I. Kaminsky, J. G. Hardman, E. W. Sutherland, and G. W. Liddle. 1970. Kinetic parameters and renal clearances of plasma adenosine $3^{\prime}, 5^{\prime}$-monophosphate and guanosine $3^{\prime}, 5^{\prime}$-monophosphate in man. J. Clin. Invest. 49:2222-2236.

35. Butlen, D., and S. Jard. 1972. Renal handling of 3'-5'-cyclic AMP in the rat. Pfluegers Arch. Eur. J. Physiol. 331:172-190.

36. Vesely, D. L. 1981. Angiotensin II stimulates guanylate cyclase activity in aorta, heart, and kidney. Am. J. Physiol. 240 (Endocrinol. Metab. 3):E391-E393.

37. Tremblay, J., R. Gerzer, P. Vinay, S. C. Pang, R. Beliveau, and P. Hamet. 1985. The increase in cGMP by atrial natriuretic factor correlates with the distribution of particulate guanylate cyclase. FEBS (Fed. Eur. Biochem. Soc.) Lett. 181:17-22.

38. Huang, C.-L., H. E. Ives, and M. G. Cogan. 1986. In vivo evidence that CGMP serves as the second messenger for atrial natriuretic factor. Proc. Natl. Acad. Sci. USA. 83:8015-8018. 